\title{
DETERMINATION OF OPTIMAL TILT ANGLE FOR MAXIMUM SOLAR INSOLATION FOR PV SYSTEMS IN ENUGU-SOUTHERN NIGERIA
}

\author{
Y. N. Udoakah ${ }^{1, *}$ and N. I. Okpura ${ }^{2}$

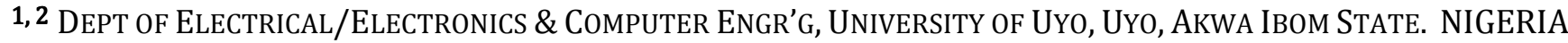 \\ Email addresses:1yeobongudokah@uniuyo.edu.ng,2nsebongokpura@uniuyo.edu.ng
}

\begin{abstract}
The energy output of photovoltaic (PV) module at different tilt angles is presented in this paper. Enugu, the study area lies within Latitude 6040'55.3"N \& longitude $7027^{\prime} 42.42^{\prime \prime} E$ and is located in southern Nigeria. The paper analyses the solar radiation data estimated from sunshine hours and ambient temperature to predict the PV energy output at the site. The analysis showed that the best tilt angle for PV energy production is $6^{\circ}$ if the module is fixed but if adjusted monthly, the best tilt angle for each month will be 300, 240, and $6^{\circ}$ for (January to March),00 for (April to September), $18^{\circ}, 30^{\circ}$ and $36^{\circ}$ for (October to December)respectively. It is found that adjusting the tilt angle of the module monthly to its optimum tilt will lead to an energy yield of $192.70 \mathrm{~W} / \mathrm{m}^{2}$. This value represents about $3 \%$ increase when compared to $186.86 \mathrm{~W} / \mathrm{m}^{2}$ obtained when the tilt angle was fixed.
\end{abstract}

Keywords: Energy output, photovoltaic module, best tilt angle, solar radiation, sunshine hours, ambient temperature

\section{INTRODUCTION}

The key to sustainable development which will lead to the gradual eradication of poverty remains access to electricity. Electricity access the world over has continued to be the driving force that propels the economy. The industrialization and development of any society is anchored on it. To say the least, the modern world is defined by the provision of a sustainable energy. Regrettably, despite the overwhelming benefits of energy, many people the world over especially in developing countries still lack or are denied access to it. Ironically, most of these regions without adequate access to electricity are regions with sufficient natural resources that can be developed to cater for her energy need. For instance, [1] noted that the position of the sun as viewed from the earth between latitudes $15^{0} \mathrm{~N}$ and $35^{\circ} \mathrm{N}$ is the region with the most solar energy. These semiarid regions are mostly located in Africa, the Middle East, the Western United State and India. Nigeria which is located in Africa is one of such countries described by [2], as being sustainably rich yet without power.

In a recent research, $[2,13]$ observed that the climatic conditions of Nigeria was quite favourable for the implementation of photovoltaic (PV) systems. The sun is known to be one of the renewable energy sources that produce a constant amount of energy. Nigeria's unique location predisposes her to be one of the major beneficiaries of this free energy. It is asserted in [3] that it was possible to meet the total energy demand of the country if only $0.1 \%$ of the total solar energy radiant on Nigeria's land mass is converted using suitable solar technology at an efficiency of $1 \%$. Also, according to [4], Nigeria has an average of $1.804 \times 10^{15}$ $\mathrm{kWh}$ of incident solar energy annually based on Nigeria land area of $924^{*} 10^{3} \mathrm{~km}^{2}$ and an average of $5.535 \mathrm{kWh} / \mathrm{m}^{2} /$ day. However, the incident power on a PV module does not only depend on the power contained in the sunlight, but also on the angle between the module and the sun as illustrated in Figure 1 (where, $\alpha$ s is the solar azimuth angle, $\alpha$ is the azimuth angle of the PV generator, $\beta$ is the tilt angle of $\mathrm{PV}$ generator and $\gamma \mathrm{s}$ is the solar elevation from the horizon). When the PV module or any other absorbing surface and the sunlight are perpendicular to each other, the power density on the surface is equal to that of the sunlight. Conversely, since the angle between the sun and a fixed surface is always changing, the power density on a fixed PV module is less than that of the incident sunlight. 


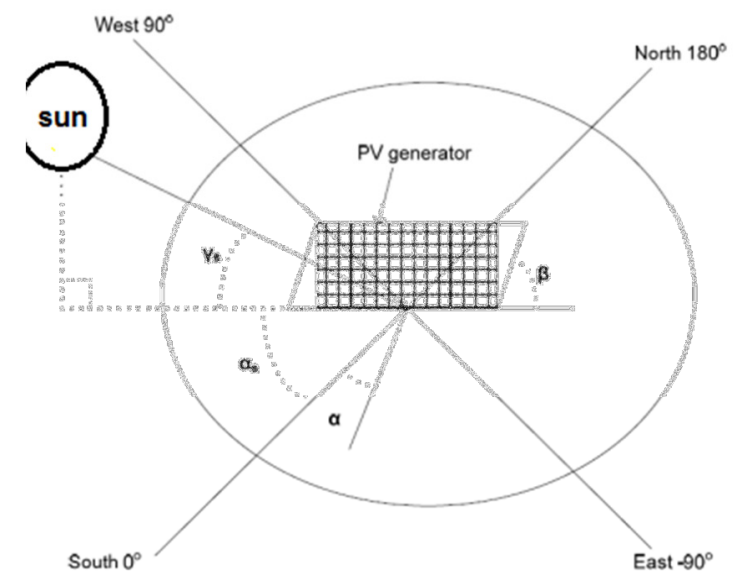

Figure 1: Schematic presentation of the inclination angle of a PV module [8]

From the foregoing, it is obvious that the positioning of the PV module determines the energy produced by it. Thus, achieving the maximum possible performance is critical in PV power generation [14]. Installing PV modules on either a single or dual-axis trackers is one of the ways of achieving this. A more economical way of optimizing the energy yield of a PV module is the determination of the optimal tilt angle on which the module would receive the maximum possible energy. As stated earlier, the tilt angle has a great impact on the solar radiation incident on a surface. For a fixed tilt angle, various studies have shown that the maximum power over the course of a year is obtained when the tilt angle is equal to the latitude of the location. For instance, [5] in their study of global, direct and diffuse solar radiation on both horizontal and tilted surfaces in Saudi Arabia came to the conclusion that solar devices must be tilted not just to face south, but also at an angle equal to the latitude of the location for best performance. The study used both the Liu and Jordan isotropic model and Klucher's anisotropic model for the determination of the solar radiation on tilted surfaces. In a similar study, [6] examined the theoretical aspects of selecting a suitable tilt angle for solar flat-plate collectors used at ten different stations in the world. Their calculation was based on measured values of monthly mean daily global and diffuse solar radiations obtained from horizontal surfaces. Based on their analysis, it was concluded that nearly optimal energy could be harnessed by varying the tilt angle seasonally. Still on the determination of maximum power output from PV systems, [7] conducted an experiment by varying the tilt angles of various PV systems at different temperatures. It was discovered that at a low temperature of $15^{\circ} \mathrm{C}$ and a tilt angle of $35^{\circ}$ which coincided with the latitude of the study area, the maximum power was achieved. The hourly prediction of solar radiation on horizontal and inclined surfaces for Muscat/Oman was performed by [11]. This was achieved using daily measured data obtained from horizontal surface. Based on this study a model and computer code capable of estimating solar radiation for the calculation of cooling load and solar collector performance was developed. With respect to Nigeria, some authors have conducted studies on horizontal global solar radiations and have also investigated the effect of orientation of PV surfaces. For instance, [9] used sunshine hours and other climate parameters to determine global solar radiations on horizontal surfaces over Enugu while [12] investigated the effects of PV orientations in three different cities (Abuja, Benin City and Katsina). Resulting from their study, three optimization methods were proposed in order to obtain increased solar radiation. However, detailed analyses of the contribution of each of the three components which sums up to give the global solar radiation at a tilted surface and the need for monthly adjustment of PV modules to correspond with the tilt angle for which optimal solar radiation can be obtained seems to be lacking in most of the reviewed literatures.

In this work, besides the determination of the monthly optimal tilt angle for maximum solar isolation for PV systems in Enugu, the percentage contribution of the beam, diffuse and albedo radiations to the global solar energy radiation at their various optimal tilt angles is also analyzed while stressing the importance of the installation of PV systems at their optimal tilt angles for an enhanced operation as reflected in the increased energy yield.

\section{MATERIALS AND METHOD}

Knowledge of solar radiation at the location of interest at any given time is vital in the design of a PV system. The solar radiation intensity falling on a surface is known as irradiance or insolation. This is measured in $\mathrm{W} / \mathrm{m}^{2}$ or $\mathrm{kW} / \mathrm{m}^{2}$. Another parameter of interest is the Irradiation, which is the total amount of solar radiation energy and is measured in $\mathrm{J} / \mathrm{m}^{2}$. Solar radiance measurements consist of global and/or direct radiation measurements taken periodically throughout the day. The measurements are taken using either a pyranometer (measuring global radiation) and/or a pyrheliometer (measuring direct radiation). In developed societies, this information is accurately collected over time and is easily accessed. 
In areas where collection of this information is not possible, due to technical or economic reasons, alternative methods are employed. Some of these methods include the use of sunshine recorders (also called Campbell-Stokes recorders) which records the duration of sunshine in a day. Data collected in this way enable spatial interpolation thus filling the gaps of missing or unavailable data and can be used to determine the solar insolation by comparing the measured number of sunshine hours to those based on calculations and including several correction factors. Several empirical models have been developed to calculate global solar radiation using various parameters. However, the model that is relevant to our site of interest was developed by [9].

An indication of how much energy is falling on a solar PV module tilted at an angle from the horizontal requires a series of complex calculations. In this work, A MATLAB code was developed using equations (1) to (11) and employed along with other climatological parameters to determine the monthly averages of the beam irradiation, the diffused radiation, the albedo radiation and the global irradiation at different tilt angles for Enugu. These codes were developed using a simplified approach as proposed in [1, 8 \&10]. The parameters used in determining the global solar radiation are as follows:

\subsection{Declination Angle ( $\delta$ )}

The declination angle could be estimated for any given day $\mathrm{n}$ using equation 1 .

$\delta=23.45 * \operatorname{Sin}(360 *(284+\mathrm{n}) / 365)$

\subsection{Hour Angle $\left(\omega_{s}\right)$}

The earth rotates one revolution per day corresponding to $360^{\circ}$ longitude $=24$ hours. This implies that the day length is $2 \times \frac{\omega \mathrm{s}}{15}$

$\omega_{\mathrm{s}}=\cos ^{-1}(-\tan \phi \tan \delta)$

Where $\boldsymbol{\phi}$ is the latitude of the location, hence the sunrise and sunset angles for a tilted surface $\left(\omega_{s}^{\prime}\right)$, facing the equator is given by;

$\omega^{\prime}{ }_{\mathrm{s}}=\cos ^{-1} \tan (\boldsymbol{\phi}-\boldsymbol{\beta}) \tan \delta$

Where $\boldsymbol{\beta}$ is the angle of tilt defined in Figure 1.

\subsection{Beam Irradiation for the Horizontal Surface $\left(B_{0}\right)$}

This is the monthly mean horizontal daily total extraterrestrial solar radiation energy given by:

$$
\begin{aligned}
B_{o}=\frac{24}{\pi} S\{1+ & \left.0.033 \cos \left(\frac{2 \pi d_{n}}{365}\right)\right\} \\
& \times\left\{\cos \phi \cos \delta \sin \omega_{\mathrm{s}}\right. \\
& \left.+\omega_{\mathrm{s}} \sin \phi \sin \delta\right\}
\end{aligned}
$$

Where $d_{n}$ is the day of the year, $S$ is the solar constant equal to $1367 \mathrm{~W} / \mathrm{m}^{2}$ and $\omega_{0}=\min \left\{\omega_{\mathrm{s}}, \omega_{\mathrm{s}}^{\prime}\right\}$

\subsection{Clearness Index (KT)}

This is the ratio of the monthly mean horizontal daily radiation to the monthly mean horizontal daily total extraterrestrial solar radiation.

$$
K T=\frac{\mathrm{G}}{\mathrm{Bo}}
$$

$\mathrm{G}$ is the monthly mean horizontal daily terrestrial solar radiation otherwise known as the solar irradiation data of the area. $G$ can either be referenced from weather station data or calculated from sunshine hours using the relationship $B o *\left\{a+b\left(\frac{s}{s o}\right)\right\}$. Where $\mathrm{a}$ and $\mathrm{b}$ are empirical constants, $\mathrm{s}$ is the recorded sunshine hours and so is the day length [9-10].

\subsection{Diffused Irradiation (D)}

This is the monthly average daily value for the diffused irradiation incident on a horizontal surface.

$$
\mathrm{D}=\mathrm{G} *(1-1.13 \mathrm{KT})
$$

\subsection{The Beam Irradiation (B) on a Tilted Surface}

This is the beam irradiation component incident on a horizontal surface on the average day for each month.

$$
\mathrm{B}=\mathrm{G}-\mathrm{D}
$$

$$
\begin{aligned}
& \text { 2.7 The Beam Irradiation } \mathbf{B}(\boldsymbol{\beta}) \text { at an Angle } \\
& B(\beta) \\
& =B \frac{\cos (\phi-\beta) \cos \delta \sin \omega_{0}+\omega_{\mathrm{s}} \sin (\phi-\beta) \sin \delta}{\cos \phi \cos \delta \times \sin \omega_{\mathrm{s}}+\omega_{\mathrm{s}} \sin \phi \sin \delta}
\end{aligned}
$$

\subsection{The Diffused Radiation D $(\boldsymbol{\beta})$ on a Tilted Surface}

$$
D(\beta)=\frac{1}{2} \times \mathrm{D} \times(1+\cos (\beta))
$$

\subsection{The Albedo Radiation or Reflected Component $\mathrm{R}$ $(\boldsymbol{\beta})$ on a Tilted Surface}

In calculating this, it is assumed that no reflected radiation is incident on a horizontal plane.

$$
R(\beta)=\frac{1}{2} \times B \times \rho \times(1-\cos (\beta))
$$

Where reflectivity ( $\boldsymbol{\rho}$ ) was taken to be 0.25

\subsection{The Global Irradiation or Total Irradiation G $(\boldsymbol{\beta})$ on a Tilted Surface}

Adding the beam irradiation, the diffused radiation and the albedo radiation results in the monthly average daily global irradiation at a given tilt angle.

$\mathrm{G}(\boldsymbol{\beta})=\mathrm{B}(\boldsymbol{\beta})+\mathrm{D}(\boldsymbol{\beta})+\mathrm{R}(\boldsymbol{\beta})$ 


\section{RESULTS AND DISCUSSION}

The monthly averages of daily global irradiation, the beam irradiation, the diffused and reflected radiation at various tilt angles generated from MATLAB based on the code developed using equations (1) to (11) are presented in Tables 1 and 2.

The irradiation in $\left(\mathrm{MJ} / \mathrm{m}^{2}\right)$ for tilt angles variation of 0 $-72^{0}$ with steps of 6 for the various months is shown in Table 1. From the Table, it is seen under the column for yearly average that the maximum irradiation occurs at $6^{0}$ tilt angle if the PV modules are fixed. At this tilt angle, the irradiance energy is $16.15 \mathrm{MJ} / \mathrm{m}^{2}$ $\left(186.86 \mathrm{~W} / \mathrm{m}^{2}\right)$. However, if it is possible for the tilt angle to be adjusted monthly by the user to obtain the maximum irradiance energy corresponding to the optimum tilt angles $\left(30^{0}, 24^{0}, 6^{0}, 0^{0}, 0^{0}, 0^{0}, 0^{0}, 0^{0}, 0^{0}\right.$, $\left.18^{0}, 30^{\circ}, 36^{\circ}\right)$, the average yearly energy yield obtained will be $192.70 \mathrm{~W} / \mathrm{m}^{2}$. Noticeably, the sum of the solar irradiation values obtained at various monthly optimal tilt angles is higher than the yearly average irradiance at $6^{\circ}$ and represents about 3\% increase in the solar radiation intensity.

In Tables $2 \mathrm{a}$ to $2 \mathrm{c}$, the contributions of the beam, diffuse and albedo radiations to the global solar energy radiation at the various tilt angles is presented. Many published work do not take into consideration the contribution of the albedo radiation mostly because it is considered to be small and negligible. In this work, this component was taken into account. At a glance, it is seen from the Tables recorded against the row for $0^{0}$ tilt angle that the total irradiation for horizontal surfaces is only comprised of the sum of the beam and diffused radiations. These results agree with that obtained in Table 1 and recorded against the row for $0^{0}$ tilt angle and further affirms the fact that no reflected radiation is incident on a horizontal plane.

Table 1: Monthly Average Daily Global Irradiation

\begin{tabular}{cccccccccccccc}
\hline $\begin{array}{c}\text { Tilt } \\
\text { angle }\end{array}$ & Jan. & Feb. & March & April & May & June & July & Aug. & Sept. & Oct. & Nov & Dec. & $\begin{array}{c}\text { Yearly } \\
\text { Avg. }\end{array}$ \\
\hline 0 & 16.64 & 17.66 & 16.01 & 15.95 & 16.31 & 15.73 & 14.68 & 14.62 & 15.34 & 16.20 & 16.33 & 17.11 & 16.05 \\
6 & 17.30 & 18.10 & 16.10 & 15.74 & 15.93 & 15.27 & 14.32 & 14.40 & 15.32 & 16.47 & 16.89 & 17.90 & 16.15 \\
12 & 17.83 & 18.39 & 16.06 & 15.50 & 15.42 & 14.69 & 13.85 & 14.08 & 15.20 & 16.61 & 17.32 & 18.54 & 16.12 \\
18 & 18.21 & 18.54 & 15.91 & 15.10 & 14.79 & 13.99 & 13.27 & 13.65 & 14.96 & 16.63 & 17.61 & 19.04 & 15.97 \\
24 & 18.45 & 18.54 & 15.73 & 14.58 & 14.04 & 13.18 & 12.58 & 13.12 & 14.61 & 16.52 & 17.76 & 19.38 & 15.71 \\
30 & 18.54 & 18.40 & 15.26 & 13.93 & 13.19 & 12.27 & 11.81 & 12.50 & 14.16 & 16.27 & 17.77 & 19.56 & 15.30 \\
36 & 18.48 & 18.11 & 14.76 & 13.25 & 12.24 & 11.26 & 10.94 & 11.79 & 13.60 & 15.93 & 17.64 & 19.58 & 14.80 \\
42 & 18.27 & 17.68 & 14.16 & 12.44 & 11.19 & 10.16 & 10.00 & 11.00 & 12.96 & 15.46 & 17.38 & 19.44 & 14.18 \\
48 & 17.91 & 17.11 & 13.46 & 11.52 & 10.06 & 8.97 & 8.98 & 10.13 & 12.22 & 14.87 & 16.97 & 19.14 & 13.45 \\
54 & 17.41 & 16.42 & 12.67 & 10.59 & 8.86 & 7.70 & 7.88 & 9.20 & 11.41 & 14.17 & 16.43 & 18.68 & 12.62 \\
60 & 16.75 & 15.59 & 11.80 & 9.56 & 7.58 & 6.34 & 6.72 & 8.21 & 10.53 & 13.38 & 15.77 & 18.07 & 11.69 \\
72 & 15.11 & 13.62 & 9.85 & 7.32 & 4.68 & 2.94 & 3.98 & 6.05 & 8.60 & 11.52 & $14.10 s$ & 16.43 & 9.52 \\
\hline
\end{tabular}

Table 2a: Beam Irradiation, Diffused and Reflected Radiation for January to April

\begin{tabular}{ccccccccccccc}
\hline & \multicolumn{3}{c}{ Jan. } & \multicolumn{3}{c}{ Feb. } & \multicolumn{3}{c}{ March } & April \\
\hline Tilt angle & $\mathrm{B}(\mathrm{B})$ & $\mathrm{D}(\mathrm{B})$ & $\mathrm{R}(\mathrm{B})$ & $\mathrm{B}(\mathrm{B})$ & $\mathrm{D}(\mathrm{B})$ & $\mathrm{R}(\mathrm{B})$ & $\mathrm{B}(\mathrm{B})$ & $\mathrm{D}(\mathrm{B})$ & $\mathrm{R}(\mathrm{B})$ & $\mathrm{B}(\mathrm{B})$ & $\mathrm{D}(\mathrm{B})$ & $\mathrm{R}(\mathrm{B})$ \\
\hline 0 & 9.21 & 7.43 & 0 & 9.78 & 7.88 & 0 & 7.60 & 8.41 & 0 & 7.39 & 8.56 & 0 \\
6 & 9.89 & 7.41 & 0.01 & 10.22 & 7.86 & 0.01 & 7.70 & 8.39 & 0.01 & 7.22 & 8.52 & 0.01 \\
12 & 10.46 & 7.35 & 0.03 & 10.57 & 7.80 & 0.03 & 7.72 & 8.32 & 0.02 & 7.01 & 8.47 & 0.02 \\
18 & 10.91 & 7.24 & 0.06 & 10.79 & 7.69 & 0.06 & 7.66 & 8.20 & 0.05 & 6.70 & 8.35 & 0.05 \\
24 & 11.24 & 7.11 & 0.10 & 10.90 & 7.54 & 0.11 & 7.56 & 8.09 & 0.08 & 6.31 & 8.19 & 0.08 \\
30 & 11.45 & 6.93 & 0.15 & 10.88 & 7.35 & 0.16 & 7.28 & 7.85 & 0.13 & 5.84 & 7.97 & 0.12 \\
36 & 11.54 & 6.72 & 0.22 & 10.75 & 7.13 & 0.23 & 6.97 & 7.61 & 0.18 & 5.33 & 7.74 & 0.18 \\
42 & 11.50 & 6.47 & 0.30 & 10.50 & 6.87 & 0.31 & 6.59 & 7.33 & 0.24 & 4.75 & 7.46 & 0.23 \\
48 & 11.33 & 6.20 & 0.38 & 10.13 & 6.58 & 0.40 & 6.13 & 7.02 & 0.31 & 4.09 & 7.12 & 0.30 \\
54 & 11.04 & 5.90 & 0.47 & 9.65 & 6.26 & 0.50 & 5.60 & 6.68 & 0.39 & 3.41 & 6.80 & 0.38 \\
60 & 10.61 & 5.56 & 0.58 & 9.07 & 5.91 & 0.61 & 5.02 & 6.31 & 0.47 & 2.67 & 6.42 & 0.46 \\
72 & 9.46 & 4.86 & 0.80 & 7.61 & 5.16 & 0.84 & 3.68 & 5.51 & 0.66 & 1.08 & 5.60 & 0.63 \\
\hline
\end{tabular}

Table 2b: Beam Irradiation, Diffused and Reflected Radiation for May to August

\begin{tabular}{|c|c|c|c|c|c|c|c|c|c|c|c|c|}
\hline & \multicolumn{3}{|c|}{ May } & \multicolumn{3}{|c|}{ June } & \multicolumn{3}{|c|}{ July } & \multicolumn{3}{|c|}{ Aug. } \\
\hline Tilt angle & $B(B)$ & $D(B)$ & $R(B)$ & $\mathrm{B}(\mathrm{B})$ & $D(B)$ & $R(B)$ & $\mathrm{B}(\mathrm{B})$ & $\mathrm{D}(\mathrm{B})$ & $R(B)$ & $B(B)$ & $D(B)$ & $R(B)$ \\
\hline 0 & 7.74 & 8.57 & 0 & 7.29 & 8.44 & 0.00 & 6.30 & 8.38 & 0 & 6.28 & 8.34 & 0 \\
\hline 6 & 7.38 & 8.55 & 0.0053 & 6.85 & 8.42 & 0.01 & 5.96 & 8.35 & 0.00 & 6.08 & 8.32 & 0.00 \\
\hline
\end{tabular}




\begin{tabular}{|c|c|c|c|c|c|c|c|c|c|c|c|c|}
\hline & \multicolumn{3}{|c|}{ May } & \multicolumn{3}{|c|}{ June } & \multicolumn{3}{|c|}{ July } & \multicolumn{3}{|c|}{ Aug. } \\
\hline Tilt angle & $B(B)$ & $D(B)$ & $R(B)$ & $B(B)$ & $\mathrm{D}(\mathrm{B})$ & $R(B)$ & $B(B)$ & $\mathrm{D}(\mathrm{B})$ & $R(B)$ & $B(B)$ & $D(B)$ & $R(B)$ \\
\hline 12 & 6.91 & 8.48 & 0.0211 & 6.32 & 8.35 & 0.02 & 5.54 & 8.28 & 0.02 & 5.81 & 8.25 & 0.02 \\
\hline 18 & 6.38 & 8.36 & 0.0474 & 5.71 & 8.24 & 0.04 & 5.06 & 8.17 & 0.04 & 5.47 & 8.14 & 0.04 \\
\hline 24 & 5.76 & 8.20 & 0.0837 & 5.03 & 8.08 & 0.08 & 4.50 & 8.01 & 0.07 & 5.07 & 7.98 & 0.07 \\
\hline 30 & 5.06 & 8.00 & 0.1296 & 4.27 & 7.88 & 0.12 & 3.89 & 7.82 & 0.11 & 4.61 & 7.78 & 0.10 \\
\hline 36 & 4.30 & 7.75 & 0.1848 & 3.45 & 7.64 & 0.17 & 3.22 & 7.58 & 0.15 & 4.09 & 7.55 & 0.15 \\
\hline 42 & 3.47 & 7.47 & 0.2485 & 2.56 & 7.36 & 0.23 & 2.50 & 7.30 & 0.20 & 3.52 & 7.27 & 0.20 \\
\hline 48 & 2.59 & 7.15 & 0.3201 & 1.62 & 7.05 & 0.30 & 1.73 & 6.99 & 0.26 & 2.91 & 6.96 & 0.26 \\
\hline 54 & 1.66 & 6.80 & 0.3989 & 0.62 & 6.70 & 0.38 & 0.91 & 6.65 & 0.32 & 2.26 & 6.62 & 0.32 \\
\hline 60 & 0.66 & 6.43 & 0.4838 & -0.45 & 6.33 & 0.46 & 0.04 & 6.28 & 0.39 & 1.56 & 6.26 & 0.39 \\
\hline 72 & -1.60 & 5.60 & 0.6686 & -3.22 & 5.33 & 0.63 & -2.05 & 5.48 & 0.54 & 0.05 & 5.46 & 0.54 \\
\hline
\end{tabular}

Table 2c: Beam Irradiation, Diffused and Reflected Radiation for September to December

\begin{tabular}{|c|c|c|c|c|c|c|c|c|c|c|c|c|}
\hline & \multicolumn{3}{|c|}{ Sept. } & \multicolumn{3}{|c|}{ Oct. } & \multicolumn{3}{|c|}{ Nov. } & \multicolumn{3}{|c|}{ Dec. } \\
\hline Tilt angle & $B(B)$ & $D(B)$ & $R(B)$ & $\mathrm{B}(\mathrm{B})$ & $\mathrm{D}(\mathrm{B})$ & $R(B)$ & $\mathrm{B}(\mathrm{B})$ & $D(B)$ & $R(B)$ & $\mathrm{B}(\mathrm{B})$ & $\mathrm{D}(\mathrm{B})$ & $R(B)$ \\
\hline 0 & 6.93 & 8.41 & 0 & 8.05 & 8.15 & 0 & 8.68 & 7.66 & 0 & 9.86 & 7.25 & 0 \\
\hline 6 & 6.94 & 8.38 & 0.00 & 8.34 & 8.12 & 0.01 & 9.25 & 7.64 & 0.01 & 10.66 & 7.23 & 0.01 \\
\hline 12 & 6.86 & 8.31 & 0.02 & 8.54 & 8.06 & 0.02 & 9.72 & 7.57 & 0.02 & 11.35 & 7.17 & 0.03 \\
\hline 18 & 6.71 & 8.20 & 0.04 & 8.64 & 7.95 & 0.05 & 10.09 & 7.47 & 0.05 & 11.91 & 7.07 & 0.06 \\
\hline 24 & 6.49 & 8.04 & 0.07 & 8.64 & 7.79 & 0.09 & 10.34 & 7.33 & 0.09 & 12.34 & 6.94 & 0.11 \\
\hline 30 & 6.20 & 7.84 & 0.12 & 8.53 & 7.60 & 0.13 & 10.48 & 7.14 & 0.15 & 12.63 & 6.76 & 0.17 \\
\hline 36 & 5.83 & 7.60 & 0.17 & 8.37 & 7.37 & 0.19 & 10.51 & 6.93 & 0.21 & 12.79 & 6.56 & 0.24 \\
\hline 42 & 5.40 & 7.33 & 0.22 & 8.07 & 7.10 & 0.26 & 10.42 & 6.67 & 0.28 & 12.80 & 6.32 & 0.32 \\
\hline 48 & 4.92 & 7.02 & 0.29 & 7.74 & 6.80 & 0.33 & 10.22 & 6.39 & 0.36 & 12.68 & 6.05 & 0.41 \\
\hline 54 & 4.38 & 6.67 & 0.36 & 7.29 & 6.47 & 0.42 & 9.91 & 6.08 & 0.45 & 12.42 & 5.76 & 0.51 \\
\hline 60 & 3.79 & 6.30 & 0.43 & 6.76 & 6.11 & 0.50 & 9.49 & 5.74 & 0.54 & 12.02 & 5.44 & 0.62 \\
\hline 72 & 2.50 & 5.50 & 0.60 & 5.49 & 5.33 & 0.70 & 8.33 & 5.01 & 0.75 & 10.83 & 4.74 & 0.85 \\
\hline
\end{tabular}

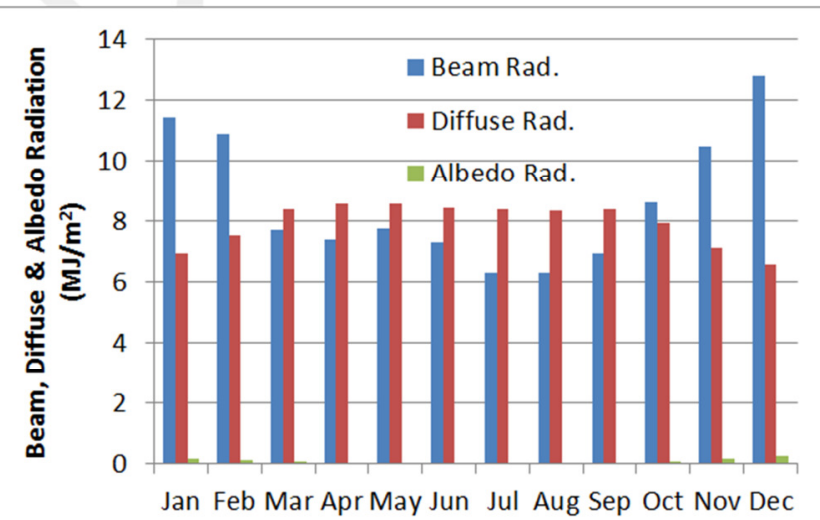

Months

Figure 2: Contributions of the Beam, Diffuse and Albedo Radiations to the Global Solar Radiation at the Various Optimal Angles

For all tilt angles, the diffuse and albedo radiations exhibit a dissimilar pattern. While the values of the diffuse radiation decreased as the tilt angle values increased, the values of the albedo radiation increased with increase in tilt angle. It was noted that the highest percentage contribution (1.2\%) of the albedo radiation to the total solar radiation was in December, while the highest percentage contribution of the beam and diffused radiations was 65 and $57.1 \%$ in December and July respectively. Also, the overall contribution of the beam, diffuse and albedo radiations to the global solar radiation at optimal

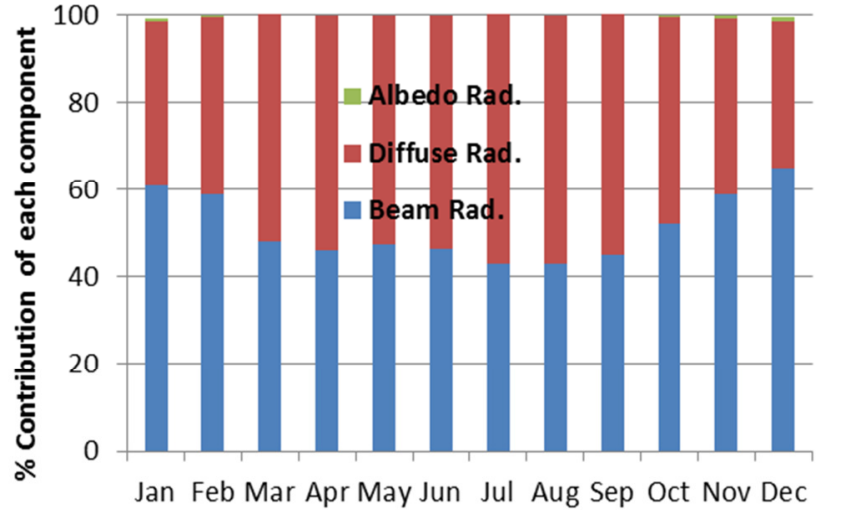

Months

Figure 3: Percentage Contributions of the Beam, Diffuse and Albedo Radiations to the Global Solar Radiation at the Various Optimal Angles

angles for Enugu were 51.9, 47.7 and $0.4 \%$ respectively. The values of the beam, diffuse and albedo radiations and their percentage contributions to the global solar radiation at the various optimal angles is presented Figures 2 and 3 respectively.

The graph in Figure 4 is a plot of the optimal angles against the months. It is visible from the plot that between the months of April to September, the optimum irradiation is achieved when the tilt angle is at $0^{0}$. 


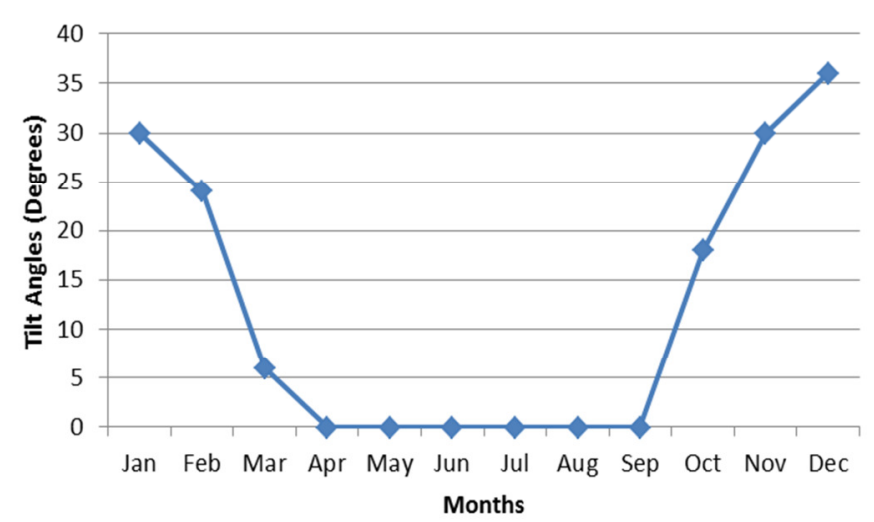

Figure 4: Optimum average tilt angle for each month from January to December.

This period corresponds with the rainy season periods in Nigeria. While between the months of Octobers to March, corresponding to the dry season period the optimum irradiation is achieved when the tilt angle is $18,30,36,30,24$ and $6^{0}$ respectively.

\section{CONCLUSION}

Using relevant meteorological parameters and the methods described in this study, monthly averages of the beam irradiation, the diffused radiation, the albedo radiation and the global irradiation at different tilt angles for Enugu was determined. The effects and contributions of each of the components (beam, diffuse and albedo) for the general case and at their optimum angles were highlighted. Result from the study shows that, using the tilt angle that yields the optimum irradiation for each month can substantially increase PV energy production. For Enugu, the average annual maximum irradiation could be obtained at a tilt angle of about $6^{0}$ which is approximately equal to the latitude of the location. Also, the contribution of the beam, diffuse and albedo radiations to the global solar radiation at optimal angles for Enugu were 51.9, 47.7 and $0.4 \%$ respectively. The results obtained could be used to estimate the KWh generation of a PV module at any site of interest within the study area.

\section{REFERENCES}

[1] A. Keyhani, Design of Smart Power Grid Renewable Energy Systems. John Wiley \& Sons, Inc., New Jersey, 2011.

[2] Y. Udoakah, and M. Umoh, "Sustainably Meeting the Energy Needs of Nigeria: The Renewable Options,"
In: Proceedings of the IEEE International Energy Conference (ENERGYCON) pp. 326-332, 2014.

[3] I. Bugaje, "Renewable energy for sustainable development in Africa: a review, "Renewable and Sustainable Energy Reviews, vol. 10, no. 6, pp. 603$612,2006$.

[4] C. Augustine, and M. Nnabuchi, "Relationship between global solar radiation and sunshine hours for Calabar, Port Harcourt and Enugu, Nigeria," International Journal of Physical Sciences, vol. 4, no. 4, pp. 182-188, 2009.

[5] A. El-Sebaii, F. Al-Hazmi, A. Al-Ghamdi, and S. Yaghmour, "Global, direct and diffuse solar radiation on horizontal and tilted surfaces in Jeddah, Saudi Arabia," Applied Energy, vol. 87, pp. 568-576, 2010.

[6] M. Ahmad, and G. Tiwari, "Optimization of Tilt Angle for Solar Collector to Receive Maximum Radiation, “The Open Renewable Energy Journal, vol.2, pp. 1924, 2009.

[7] M. Hanif, M. Ramzan, M. Rahman, M. Khan, M. Amin, and M. Aamir, "Studying Power Output of PV Solar Panels at Different Temperatures and Tilt Angles," ISESCO Journal of Science and Technology, Vol. 8, No. 14, pp. 9-12, 2012.

[8] E. Taymur, Photovoltaic System Sizing [thesis]. Columbs: The Ohio State University, 2009.

[9] U. Akpan, and M. Umoh, "Horizontal Global Solar Radiation Based on Sunshine Hours Over Enugu, Nigeria" Canadian Journal of Pure \& Applied Sciences, Vol. 5, No. 2, pp. 1553-1557, 2011.

[10] T. Markvart, and L. Castaner, Practical handbook of photovoltaics fundamentals and applications. Amsterdam: Elsevier, 2003.

[11] N. Al-Rawahi, Y. Zurigat, and N. Al-Azri, "The hourly prediction of solar radiation on horizontal and inclined surfaces for Muscat/Oman, The Journal of Engineering Research, vol. 8, No. 2, pp. 19-31, 2011.

[12] M. Okundamiya, and A. Nzeako, "Influence of Orientation on the Performance of a Photovoltaic Conversion System in Nigeria," Research Journal of Applied Sciences, Engineering and Technology, vol. 3, No. 12, pp. 1384-1390, 2011.

[13] Nnadi, D. B. N. "Environmental/Climatic Effect on Stand-Alone Solar Energy Supply Performance for Sustainable Energy", Nigerian Journal of Technology, Vol. 31, No. 1, 2012, pp.79-88.

[14] Onuoha, D. V. C. "Dynamic Modeling of Natural Convection Solar Energy Flat Plate Collector for Agricultural Driers II - Validation of Solution Equations, Nigerian Journal of Technology, Vol. 26, No. 2, 2007, pp.99-105. 